\title{
Traumatic lumbar spondylolisthesis resulting in complete thoracic spinal cord avulsion: an unusual presentation
}

\author{
Jamie Toms, MD, David L. Boyer, BS, Craig R. Kelman, MD, and Rafael A. Vega, MD, PhD \\ Department of Neurosurgery, Virginia Commonwealth University Health System, Medical College of Virginia, Richmond, Virginia \\ Traumatic spondylolisthesis is a known occurrence in trauma, but complete cord transection is relatively rare. Moreover, \\ complete cord transection at a site distant from the traumatic spondylolisthesis without spondyloptosis is exceedingly \\ rare. In this report, authors describe the first case of thoracic cord avulsion following a traumatic grade II lumbar spondy- \\ lolisthesis. The unusual presentation of this case highlights the importance of further evaluating patients with neurologi- \\ cal symptoms out of proportion with the injuries seen on initial imaging. Magnetic resonance imaging performed after \\ initial imaging studies demonstrated T11 cord transection with the distal cord herniating into the lumbar paraspinal soft \\ tissues, thus allowing for preoperative planning to prepare for a more significant intervention including complex dural \\ repair and lumbar drain placement, in addition to instrumented fusion to stabilize the traumatic spondylolisthesis. \\ https://thejns.org/doi/abs/10.3171/2018.5.SPINE17919
}

KEYWORDS cord transection; motor vehicle collision; spinal cord injury; spondylolisthesis; trauma; lumbar; thoracic

$\mathrm{S}$ PINAL cord injury is a significant problem in the US and worldwide. Its incidence in the US is estimated to be 54 cases per million people per year with a current prevalence of about 285,000 individuals with spinal cord injury. ${ }^{6}$ There are multiple types of spinal cord injuries, including compression fractures, distraction injuries, lateral flexion injuries, torsional injuries, and distractive extension injuries. Traumatic spondylolisthesis is less common, especially in situations in which there is transection of the spinal cord. ${ }^{1,4}$

Spinal cord transections most commonly occur as a result of spondyloptosis in the thoracic spine where the diameter of the spinal canal is small. ${ }^{3}$ When cord avulsion occurs, the site of transection is at or near the level of the spinal cord injury. ${ }^{2}$ Here we present a case of traumatic lumbar spondylolisthesis at L4-5 that resulted in a total avulsion of the thoracic spinal cord at T11. To our knowledge, this relatively moderate lumbar spondylolisthesis (grade II) has not been reported to be associated with a complete spinal cord transection.

\section{Case Report}

History and Examination

An 18-year-old female presented to the emergency de- partment as a transfer from an outside facility. She had been a restrained passenger in a high-speed motor vehicle collision. At the outside hospital, she had undergone an abdominal ultrasound that was positive for blood, and prior to her transfer, an exploratory laparotomy was performed to remove damaged bowel. Upon arrival at our facility, she had a Glasgow Coma Scale score of 15. She was complaining of back and pelvic pressure and an inability to move her lower extremities. Her abdomen had been left open and packed from the outside hospital.

On physical examination, she was found to have Medical Research Council (MRC) grade 5/5 strength in her upper extremities and MRC grade 0/5 strength in her lower extremities. She was diffusely hypotonic and areflexic in the lower extremities. Sensation to pinprick, temperature, and proprioception was absent from the T11 dermatome and lower. She also had no anal sphincter tone or reflexes. At the time of her arrival, she was designated as having a T11 American Spinal Injury Association (ASIA) Impairment Scale score A.

Computed tomography scanning on arrival revealed acute traumatic retrolisthesis of L4 on L5 with about 10 $\mathrm{mm}$ of posterior displacement, designated grade II spondylolisthesis (Fig. 1). There was also a displaced fracture

ABBREVIATIONS MRC $=$ Medical Research Council.

SUBMITTED February 21, 2018. ACCEPTED May 11, 2018

INCLUDE WHEN CITING Published online September 7, 2018; DOI: 10.3171/2018.5.SPINE17919. 


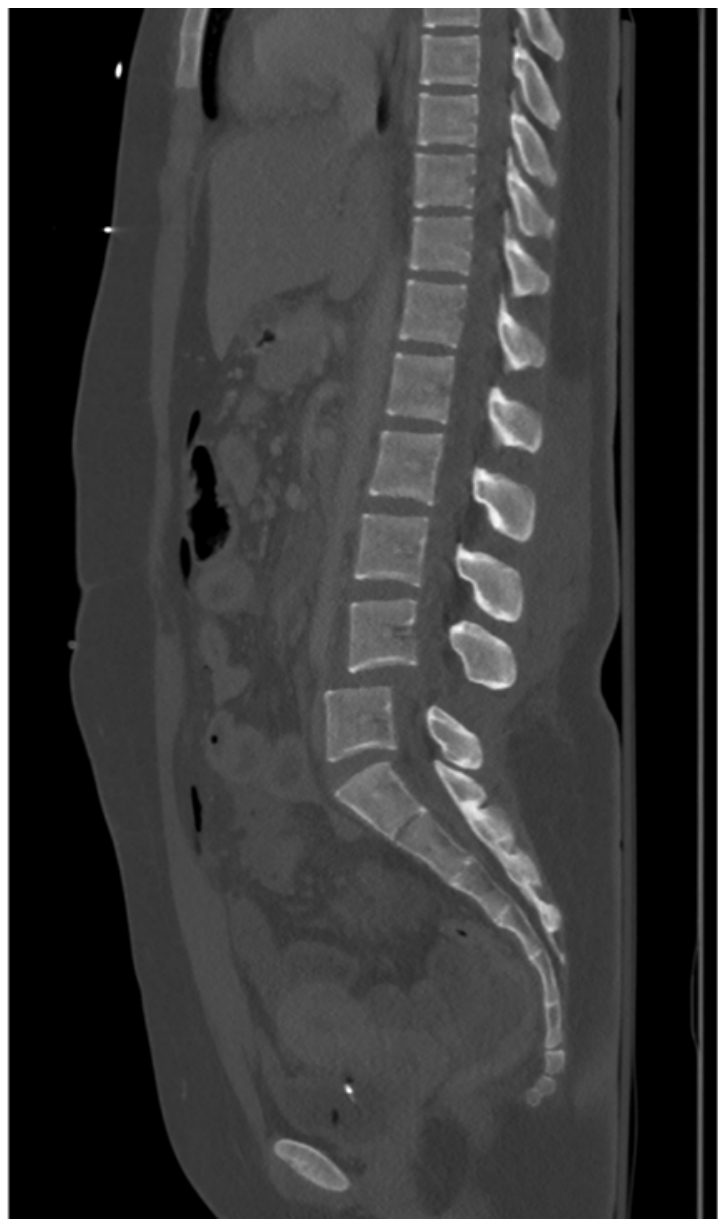

FIG. 1. Computed tomography scan demonstrating acute traumatic grade II lumbar spondylolisthesis of L4 on L5 with $10 \mathrm{~mm}$ of posterior displacement.

of the right superior articular facet on L5. To fully work up and explain this young woman's physical exam and to prepare for surgery, we performed an urgent MRI study of her thoracic and lumbar spine. The results showed complete transection of the spinal cord at the level of T11 and herniation of the dura and spinal canal contents through the ligamentum flavum. Imaging also revealed disc disruption at L4-5 (Fig. 2).

\section{Operation}

The patient's abdomen was closed via trauma surgery on hospital day 2, and the following day, she went to the operating room with our service for an open reduction of the L4-5 fracture, L4-5 laminectomies, and posterior lateral lumbar fusion of L4-S1. Initially, a large amount of cerebrospinal fluid was noted to be spilling out once the fascial layers had been opened. After the laminectomy was performed, a large dural defect was noted. A large piece of spinal cord could be seen in the caudal portion of the dural sac with clumping of the nerve roots surrounding it (Fig. 3). This nerve root-conus bundle was brought up into the dura, and the dura was primarily closed around it. Once repaired, the herniated disc at L4-5 was removed

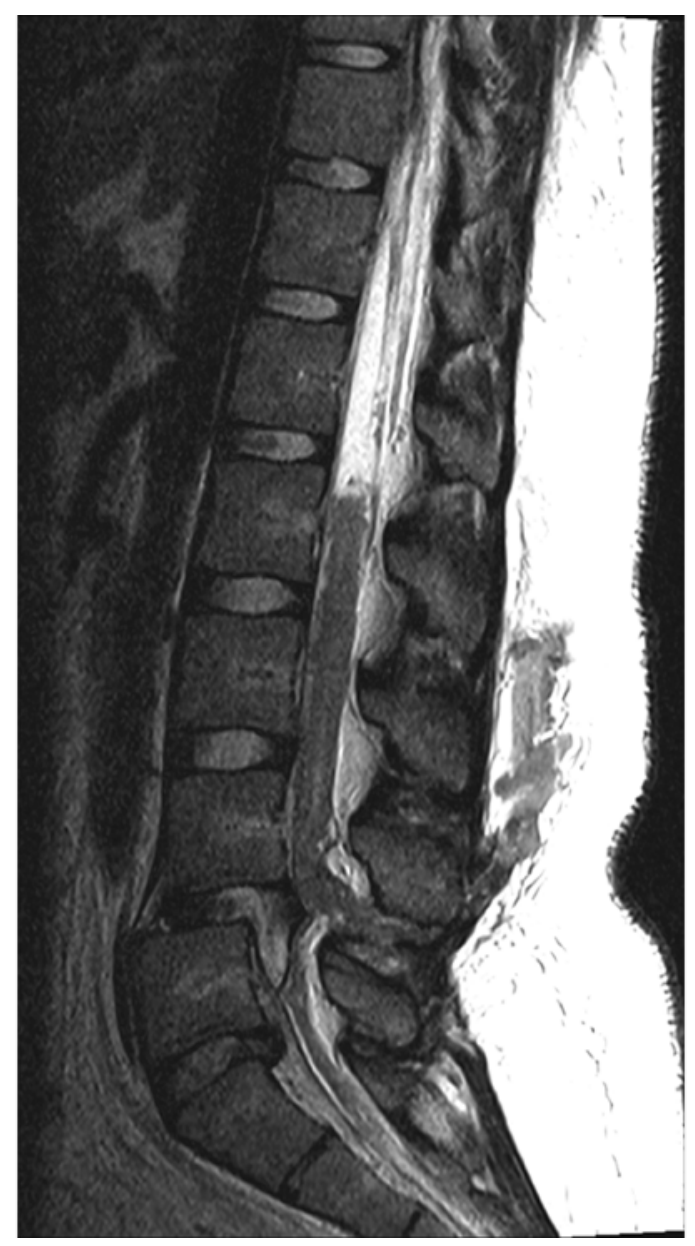

FIG. 2. Preoperative MR image of the thoracolumbar spine revealing complete transection of the spinal cord at the level of T11 and herniation of the dura and spinal canal contents through the ligamentum flavum at the level of the lumbar disc disruption at L4-5.

and pedicle screws were placed from L4 to L5 (Fig. 4). At the end of the procedure, a lumbar drain was placed and draining occurred at a rate of $10 \mathrm{ml} / \mathrm{hr}$.

\section{Postoperative Course}

The patient did not have a spinal fluid leak, and her lumbar drain was removed on postoperative day 5 . She did relatively well in rehabilitation; however, at 2 years postsurgery, she had not regained any lower-extremity function. She also battles with recurrent pressure ulcers. Magnetic resonance imaging of the lumbar spine at 2 years demonstrated regions of atrophic changes as well as irregular cystic replacement of the normal thecal sac and no visible nerve roots below the level of injury at T11 (Fig. 5).

\section{Discussion}

We present a patient with traumatic grade II lumbar spondylolisthesis of L4-5 following a motor vehicle collision. This patient also concurrently experienced a tragic transection of her thoracic spinal cord at the level of T11, which ultimately became a complete spinal cord injury. Of 


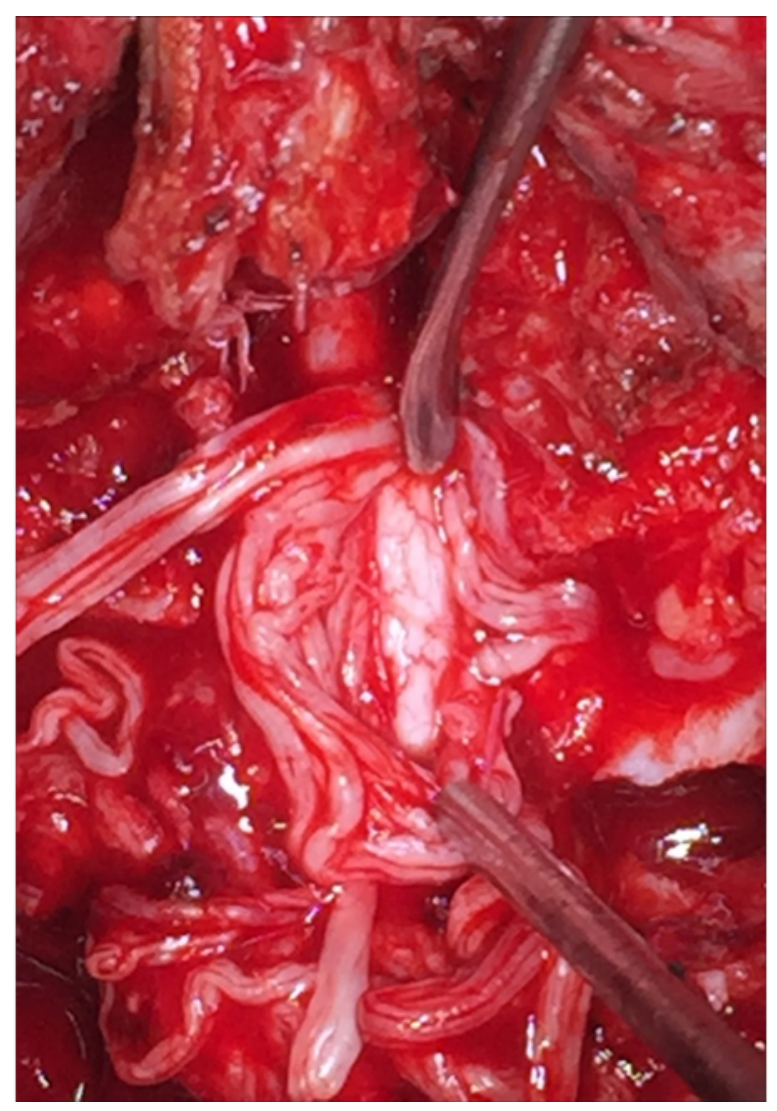

FIG. 3. Portion of the transected thoracic spinal cord seen in the caudal region of the dural sac in the lumbar spine with clumping of the nerve roots surrounding the field. Figure is available in color online only.

significance, her spinal cord avulsion occurred at a level much higher than her lower lumbar traumatic injury. Unlike other cases reported in the literature, she did not present with a complete spondyloptosis. ${ }^{2,3,5}$

Complete cord transection due to trauma is very rare, and those that involve the thoracolumbar junction are even rarer. Only about $15 \%$ of all spinal cord injuries involve the thoracolumbar junction. ${ }^{4,6}$ Spondyloptosis, greater than $100 \%$ traumatic subluxation of one vertebral body, is, although rare, a cause of complete cord transection. ${ }^{2}$ These types of fractures involve shear stress on the vertebral bodies, and most reported cases involve falls or motor vehicle accidents. ${ }^{5,7,8}$ Our case represents a unique situation in which the patient had a significant spondylolisthesis of L4-5 but not a complete spondyloptosis. This finding supports a recommendation to obtain further imaging studies (e.g., MRI) when the clinical exam does not correlate with the initial findings on radiography or CT, even in cases of mild to moderate spinal trauma.

Our patient experienced a complete cord transection at T11, which was five segments higher than her ligamentous injury at L4-5. The reason for such an injury is not fully known; however, one can theorize that it resulted from significant stretching of the lumbosacral nerve roots in the cauda equina, leading to a transmission of the force of traction to the cord and subsequent avulsion. ${ }^{1}$ On imaging, there is continuous spinal cord debris traversing between

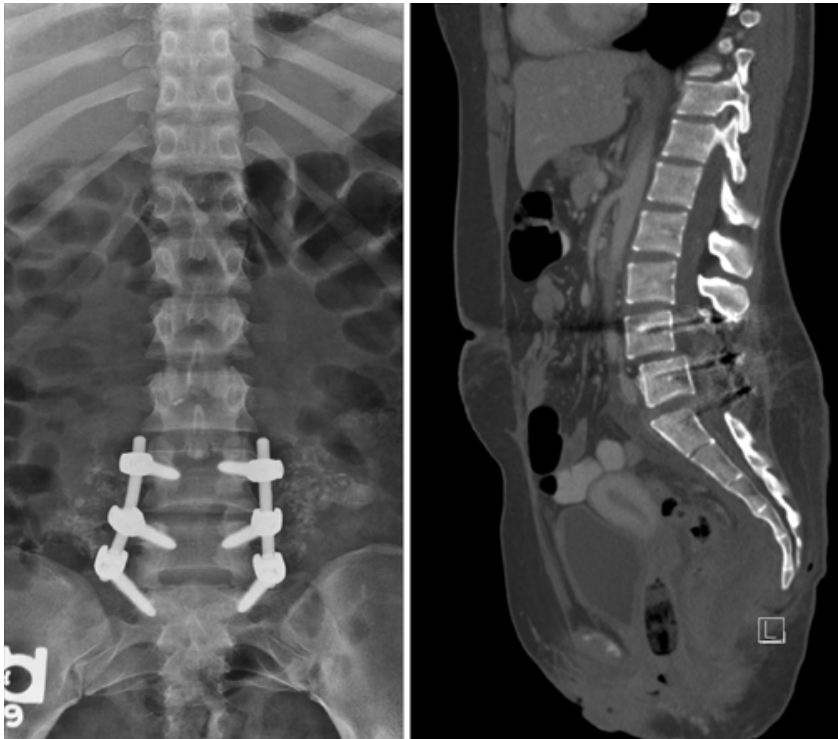

FIG. 4. Postoperative imaging. Left: Radiograph with anteroposterior projection. Right: Sagittal CT demonstrating proper alignment of the spinal column after pedicle screw fixation.

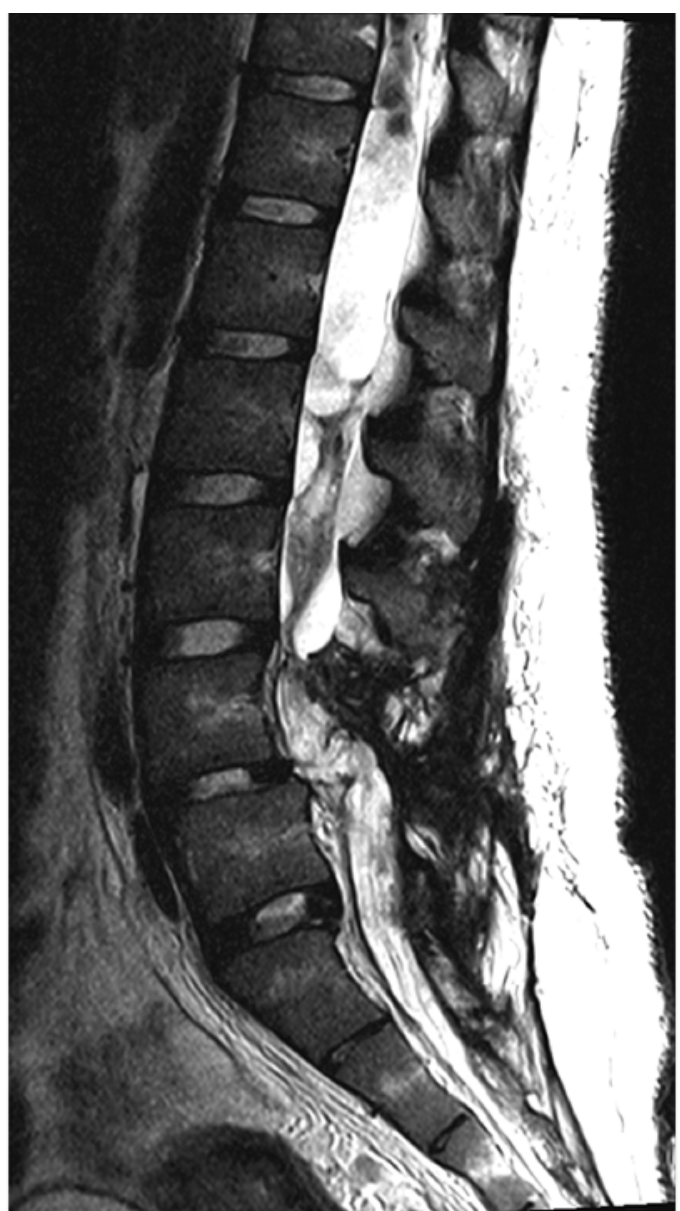

FIG. 5. Sagittal T2-weighted MR image of the thoracolumbar spine obtained at the 2-year follow-up, revealing atrophic regions and irregular cystic replacement of the normal thecal sac within the spinal canal. Additionally, no nerve roots are visible from T11 to $L 5$. 
the spinous processes of L4 and L5 with extension into the soft tissues of the lower back, in an inferoposterior fashion. We also hypothesize that this patient likely had a low-lying cord that was possibly tethered, thus allowing shear stress to be placed on the filum during the injury. Chandrashekhara et al. has reported cord transection in a patient with a low-lying cord and spondyloptosis. ${ }^{2}$

\section{Conclusions}

We present a unique and highly unusual case of thoracic spinal cord transection following a traumatic lower lumbar spine injury. This case, coupled with a prior report in the literature, ${ }^{1}$ can remind us that it is important to continue to ask questions when the injury seen on CT does not match the patient's symptoms. Unfortunately, this patient became completely paralyzed from the traumatic event.

\section{References}

1. Baliyan V, Shylendran S, Ajay KY, Kumar A, Gamanagatti S, Sinha S: Unusual cord transection in a patient with traumatic spondylolisthesis. Asian J Neurosurg 11:72, 2016

2. Chandrashekhara SH, Kumar A, Gamanagatti S, Kapoor K, Mukund A, Aggarwal D, et al: Unusual traumatic spondyloptosis causing complete transection of spinal cord. Int Orthop 35:1671-1675, 2011

3. Hasturk AE, Ilik K, Coven I, Ozdemir O: Unusual traumatic midthoracic spondyloptosis and its surgical management: case report. Neurol Med Chir (Tokyo) 53:887-889, 2013

4. Kraus JF, Silberman TA, McArthur DL: Epidemiology of spinal cord injury, in Benzel EC, Cahill DW, McCormack P (eds): Principles of Spinal Surgery. New York: McGrawHill Healthcare, 1996, Vol 1, pp 41-58

5. Mishra A, Agrawal D, Gupta D, Sinha S, Satyarthee GD, Singh PK: Traumatic spondyloptosis: a series of 20 patients. J Neurosurg Spine 22:647-652, 2015
6. National Spinal Cord Injury Statistical Center: Spinal Cord Injury Facts and Figures at a Glance. Birmingham, AL: University of Alabama at Birmingham, 2017 (https://www. nscisc.uab.edu/public_pages/FactsFiguresArchives/SCI\%20 Facts\%20and\%20Figures\%20at\%20a\%20Glance\%202017. pdf) [Accessed June 1, 2018]

7. Sekhon LH, Sears W, Lynch JJ: Surgical management of traumatic thoracic spondyloptosis: review of 2 cases. J Clin Neurosci 14:770-775, 2007

8. Yadla S, Lebude B, Tender GC, Sharan AD, Harrop JS, Hilibrand AS, et al: Traumatic spondyloptosis of the thoracolumbar spine. J Neurosurg Spine 9:145-151, 2008

\section{Disclosures}

The authors report no conflict of interest concerning the materials or methods used in this study or the findings specified in this paper.

\section{Author Contributions}

Conception and design: Vega. Acquisition of data: Vega, Toms, Boyer. Analysis and interpretation of data: all authors. Drafting the article: all authors. Critically revising the article: Vega, Toms, Kelman. Reviewed submitted version of manuscript: all authors. Approved the final version of the manuscript on behalf of all authors: Vega. Administrative/technical/material support: Vega. Study supervision: Vega.

\section{Correspondence}

Rafael A. Vega: Virginia Commonwealth University Health System, Medical College of Virginia, Richmond, VA. rafael.vega@ vcuhealth.org. 